\title{
Age, socioeconomic status, and mortality at the aggregate level
}

\author{
Sijmen A Reijneveld, Louise J Gunning-Schepers
}

\begin{abstract}
Study objective - Indicators of socioeconomic status are associated with age. This study aimed to analyse the influence of the age distribution on the ranking of small areas by socioeconomic status and on the association between their socioeconomic status and standardised mortality.

Design - The ranking of small areas by socioeconomic status indicators (educational level, income, and unemployment) was compared with crude values and after correction for their age structure. The age and gender standardised mortality ratios (SMRs) of these areas for the age group 1-64 years was then rank correlated with both crude and age standardised measures of socioeconomic status. Setting - This study used data for all $(n=22)$ boroughs of Amsterdam for the period 1986-91.
\end{abstract}

Main results - Correction of indicators of socioeconomic status for the age structure of the population hardly affects the ranking of Amsterdam boroughs by socioeconomic status. All rank correlations between crude and age standardised socioeconomic status measures are above 0.95. Rank correlations between SMR and these socioeconomic status measures also hardly change after correction for the age structure of boroughs except for education. Mean income per earner is the socioeconomic status indicator most strongly associated with the SMR.

Conclusions - This study shows that the age structure of Amsterdam boroughs has almost no influence on their ranking by socioeconomic status and a limited influence on the association between their socioeconomic status and SMR, except for educational level. The latter indicator has the strongest association with age. This result and theoretical considerations indicate that a correction for the age structure of the population will be more important if small areas differ little with regard to socioeconomic status, if they vary considerably in age structure, or if a given indicator of socioeconomic status shows a strong cohort effect or age association.

\section{( $\mathcal{F}$ Epidemiol Community Health 1994;48:146-150)}

The socioeconomic status (SES) or deprivation index of small areas is often used both to distribute financial means for health and social care $^{1-4}$ and to study the association between SES and health indicators, such as mortality. ${ }^{5-}$ ${ }^{15}$ In this type of application, indicators for the SES of small areas have not until now been corrected for the age structure of the populations concerned, though some indicators are strongly associated with age. The educational level of a group, for example, is highly dependent on its age distribution because of a cohort effect in educational participation. The proportion of people with only a diploma from primary school is only $6 \%$ in the $18-24$ years age group but it increases to $61 \%$ in the over 75 years age group in The Netherlands. This indicates that having only a primary school diploma is normal in the oldest cohort whereas it is an indicator of an unusual situation in the youngest one. Thus, the average SES (based among other factors on years of education) of an area is influenced by the age structure of its population, and the ranking of small areas by SES may thus be confounded by the age structure of the population.

SES ranking of small areas is used to study the relation between the SES and health of the populations of these areas. This has been done in relation to age standardised mortality, both in The Netherlands, ${ }^{56}$ in the main Dutch cities, ${ }^{7-11}$ and in parts of the United Kingdom. ${ }^{12-15}$ The impact of the age structure of small areas on the value of SES measures can hamper these studies.

Accurate measurement of the SES of small areas is also important for public health policies. Many public health authorities give priority to areas with a low ranking on available SES indicators to reduce and compensate for socioeconomic health differences. The latter is one of the objectives of the healthy cities network ${ }^{1617}$ and of separate local public health authorities, for instance of the city of Amsterdam. ${ }^{18}$ Their approach is backed by studies which show that low SES is associated with a worse health status at the individual level. ${ }^{19-21}$ The targeting in such a policy is not meant to be partially dependent on the age structure of the areas concerned.

We therefore focus on the influence that the age structure of the populations of small areas has on the measurement of their SES. Does correction of SES for the age structure of the population concerned change the ranking of these areas and does such a correction lead to a different association between the SES and age standardised mortality of these areas? We used data on SES and mortality which are obtainable for boroughs of the city of Amsterdam, the capital of The Netherlands. 


\section{Methods}

DATA

SES is usually determined by education, occupation, and income. This follows both the current practice in epidemiology, ${ }^{22}$ and the advice of a Dutch expert group on using the SES in relation to health differences. ${ }^{23}$ The data on the SES of Amsterdam boroughs were collected from various sources.

Data on education were obtained from a $2 \cdot 8 \%$ sample of the population aged 15-64 years in 1985 . The proportion of people with only a diploma from primary school or less and the proportion of those with a diploma from a higher professional body or university education as indicators of SES were considered in separate analyses.

Data on occupation were not available at a borough level, so data on unemployment were used instead. These data concerned the proportion of the population registered as jobless at the end of 1988 , the middle of the period studied.

Data on mean income per earner were based on income tax data for 1984, the latest year for which data were available.

Age specific data on all SES indicators for the entire city are presented in table 1 . These show a very clear gradient in relation to age, especially for education and unemployment.

Data on deaths and on person years in relation to age in the period 1986-91 were derived from the municipal population register. We used data on the age group 1-64 years.

Table 1 Percentage of the population in relation to educational level, unemployment, and net income and age, Amsterdam

\begin{tabular}{|c|c|c|c|c|c|}
\hline \multirow[t]{2}{*}{ Measure of socioeconomic status } & \multicolumn{5}{|c|}{ Age group (y) } \\
\hline & $16-24$ & $25-34$ & $35-49$ & $50-64$ & Total \\
\hline $\begin{array}{l}\text { Highest educational level (1985): } \\
\text { Primary education diploma only } \\
\text { Higher professional/university qualification }\end{array}$ & $\begin{array}{r}10.9 \\
0.0\end{array}$ & $\begin{array}{l}12.0 \\
11.5\end{array}$ & $\begin{array}{l}21 \cdot 0 \\
10 \cdot 0\end{array}$ & $\begin{array}{r}35.4 \\
2.5\end{array}$ & $\begin{array}{r}20 \cdot 6 \\
7 \cdot 0\end{array}$ \\
\hline
\end{tabular}

\begin{tabular}{|c|c|c|c|c|c|c|c|}
\hline & \multicolumn{7}{|c|}{ Age group (y) } \\
\hline & $16-24$ & $25-39$ & $40-49$ & $50-54$ & $55-59$ & $60-64$ & Total \\
\hline $\begin{array}{l}\text { Percentage unemployed } \\
\text { and looking for work } \\
\text { (1988) }\end{array}$ & $15 \cdot 4$ & $18 \cdot 3$ & $13 \cdot 4$ & $10 \cdot 6$ & $5 \cdot 5$ & $0 \cdot 0$ & $14 \cdot 4$ \\
\hline
\end{tabular}

\begin{tabular}{lllllll}
\hline & \multicolumn{1}{l}{ Age group $(y)$} \\
\cline { 2 - 7 } & $16-24$ & $25-34$ & $35-44$ & $45-64$ & $>65$ & Total \\
\hline $\begin{array}{l}\text { Mean yearly net income in } \\
\text { guilders/earner (1984) }\end{array}$ & 13484 & 21380 & 26810 & 28570 & 20981 & 22904 \\
\hline
\end{tabular}

Table 2 Results of a factor analysis on the ranks of crude and age standardised measures of socioeconomic status

\begin{tabular}{lccccc}
\hline & \multicolumn{2}{l}{ Crude } & & \multicolumn{2}{l}{ Age standardised } \\
\cline { 2 - 3 } \cline { 5 - 6 } Factor loadings & Factor 1 & Factor 2 & & Factor 1 & Factor 2 \\
\hline Education (diploma): & 0.32 & -0.92 & & 0.56 & -0.77 \\
$\quad$ Primary school only & 0.27 & 0.94 & & 0.17 & 0.96 \\
$\quad$ Higher professional/university & 0.98 & 0.13 & & 0.98 & 0.13 \\
Unemployment & -0.97 & 0.16 & & -0.97 & 0.17 \\
Income & 2.10 & 1.75 & & 2.36 & 1.43 \\
Eigen value & 52.4 & 43.8 & & 58.9 & 35.8 \\
Percentage of variance & & &
\end{tabular}

Infant mortality was excluded because past analyses have shown that this is registered incompletely. ${ }^{24}$ The upper age boundary was determined by examining up to which age only a negligible number of deaths occurs in nursing homes. The distribution of nursing homes and other care institutions is unequal in the different boroughs of Amsterdam, causing a migration between boroughs that is conditional on health status. For one year, 1990, additional data on the proportion of differences in mortality which could be explained by deaths occurring in these institutions were gathered. On the basis of these data the age of 65 years was used as a cut off point. Below this age only $1.7 \%$ of the variation in standardised mortality ratios (SMRs) between boroughs could be explained by deaths in institutions, as opposed to $20 \cdot 8 \%$ when using the age of 75 years as a cut off point.

All data were collected at the level of the Amsterdam boroughs $(n=17)$, which have had separate local authorities since 1988. They consist of adjacent areas united on the basis of sociocultural homogeneity. The biggest four were subdivided further to obtain areas of approximately the same population size ( $\mathrm{n}=22$; mean (SD) population during 1986-91 31500 (7020); mean proportion below age 45 years: $0 \cdot 66$, range $0 \cdot 41-0 \cdot 80$ ). Age specific data on income were not available for these latter subdivisions.

\section{MEASURES}

All SES data were used crude and standardised indirectly for age (in five-year age groups), with the total Amsterdam population in the period concerned as the standard. As an overall measure of the different SES indicators we used the first two factors from a factor analysis with varimax rotation on all crude SES measures and on all age standardised SES measures. Table 2 presents information on the structure of these factors in the 17 boroughs for which all SES data, both crude and age standardised, were available. The first factor of this analysis mainly represents income and unemployment rate (absolute value of correlation coefficients above 0.95).

Mortality data were used crude (crude mortality rates, CMRs) and indirectly standardised for age and gender (SMRs). The resulting figures for the different boroughs are given in table 3 and the SMRs separately in figure 1. Approximate $95 \%$ confidence intervals for the SMRs were computed according to Rothman. ${ }^{25}$

\section{ANALYSIS}

Firstly, correlation coefficients were computed between the ranks of the crude and age standardised SES measures, leading to Spearman correlation coefficients. Next the same was done for the SMR of the total population (1-64 years), with both the crude and the age standardised SES measures and the factors from the factor analysis. Finally, a stepwise, ordinary least squares regression analysis was per- 
Table 3 Data per Amsterdam borough for 1986-91. Numbers of deaths and person years and crude mortality per 1000 person years and standardised mortality ratios residents aged 1-64y)

\begin{tabular}{|c|c|c|c|c|c|}
\hline Borough & Deaths & $\begin{array}{l}\text { Person } \\
\text { years }\end{array}$ & $\begin{array}{l}\text { Crude } \\
\text { mortality }\end{array}$ & $\begin{array}{l}\text { Standardised } \\
\text { mortality }\end{array}$ & $95 \% C I$ \\
\hline \multicolumn{6}{|l|}{ Inner city: } \\
\hline Centre & 369 & 142076 & $2 \cdot 60$ & $1 \cdot 14$ & $1 \cdot 03,1 \cdot 26$ \\
\hline East & 342 & 123047 & $2 \cdot 78$ & 1.31 & $1 \cdot 18,1 \cdot 46$ \\
\hline West & 372 & 132405 & $2 \cdot 81$ & $1 \cdot 23$ & $1 \cdot 11,1 \cdot 36$ \\
\hline Westerpark & 487 & 165395 & $2 \cdot 94$ & 1.36 & $1 \cdot 25,1 \cdot 49$ \\
\hline Oud-West & 399 & 180031 & $2 \cdot 22$ & 1.05 & $0 \cdot 95,1 \cdot 15$ \\
\hline De Pijp & 465 & 190718 & $2 \cdot 44$ & $1 \cdot 12$ & $1 \cdot 02,1 \cdot 23$ \\
\hline Oost & 399 & 177520 & $2 \cdot 25$ & $1 \cdot 10$ & $0 \cdot 99,1 \cdot 21$ \\
\hline Zeeburg & 318 & 128789 & $2 \cdot 47$ & $1 \cdot 19$ & $1 \cdot 06,1.32$ \\
\hline Bos en Lommer & 405 & 157370 & 2.57 & 1.04 & $0 \cdot 94,1 \cdot 15$ \\
\hline de Baarsjes & 464 & 194240 & $2 \cdot 39$ & 1.05 & $0 \cdot 96,1 \cdot 15$ \\
\hline \multicolumn{6}{|l|}{ South: } \\
\hline East & 220 & 111716 & 1.97 & 0.73 & $0 \cdot 64,0 \cdot 83$ \\
\hline West & 384 & 158857 & $2 \cdot 42$ & 0.96 & $0 \cdot 87,1 \cdot 06$ \\
\hline Rivierenbuurt & 310 & 137419 & $2 \cdot 26$ & $0 \cdot 84$ & $0 \cdot 75,0 \cdot 94$ \\
\hline Watergraafsmeer & 299 & 99118 & 3.02 & 0.92 & $0 \cdot 82,1 \cdot 03$ \\
\hline \multicolumn{6}{|l|}{ North: } \\
\hline North & 554 & 220681 & $2 \cdot 51$ & $0 \cdot 81$ & $0 \cdot 75,0 \cdot 88$ \\
\hline South & 552 & 169581 & $3 \cdot 26$ & 1.05 & $0 \cdot 96,1 \cdot 14$ \\
\hline Geuzenveld Slot. & 522 & 156322 & $3 \cdot 34$ & 0.93 & $0 \cdot 86,1 \cdot 02$ \\
\hline Osdorp & 492 & 162755 & 3.02 & 0.88 & $0 \cdot 80,0 \cdot 96$ \\
\hline Slotervaart Overt. & 386 & 129113 & 2.99 & 0.87 & $0 \cdot 79,0 \cdot 96$ \\
\hline Buitenveldert & 240 & 81230 & 2.95 & $0 \cdot 71$ & $0.63,0 \cdot 81$ \\
\hline \multicolumn{6}{|l|}{ Southeast: } \\
\hline North & 568 & 270948 & $2 \cdot 10$ & $1 \cdot 14$ & $1 \cdot 05,1 \cdot 24$ \\
\hline South & 351 & 188683 & $1 \cdot 86$ & 0.88 & $0 \cdot 80,0 \cdot 98$ \\
\hline Total city & 8898 & 3478008 & 2.56 & & \\
\hline
\end{tabular}

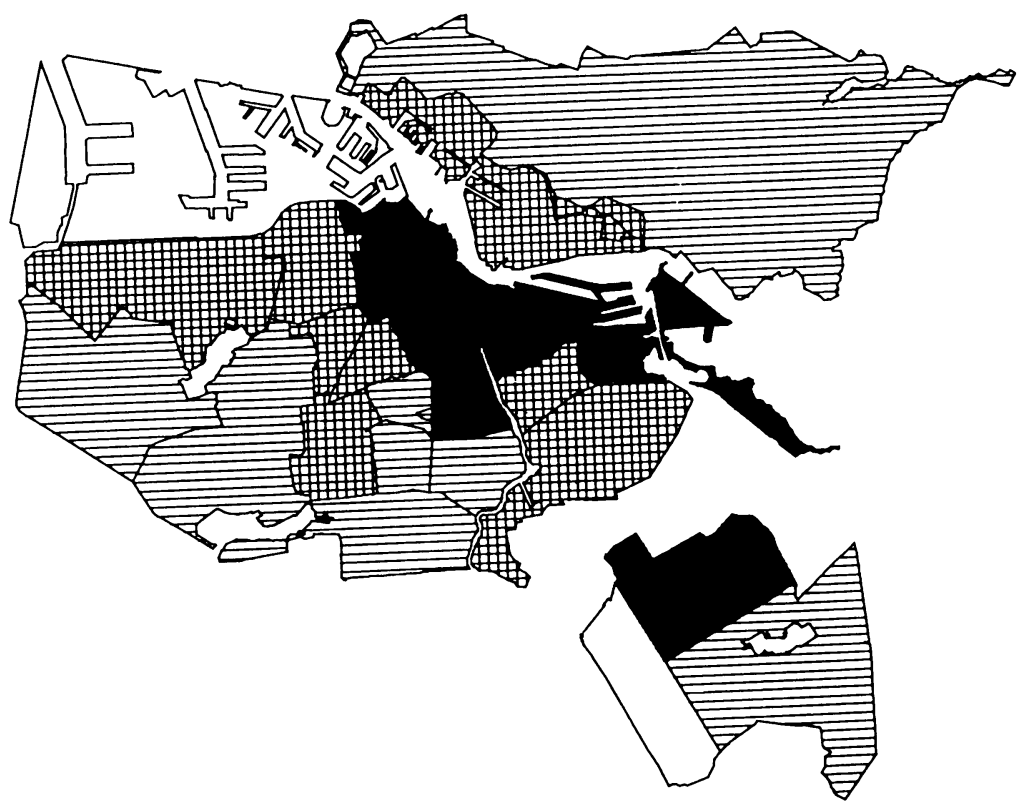

SMR significantly lower than average
SMR not significantly different from average
SMR significantly higher than average
$\square$ Harbour/industrial area

Figure 1 Distribution of standardised mortality ratios (SMR) per borough in Amsterdam, 1986-91. formed on all crude and age standardised SES measures, with and without inclusion of the respective factors. Both forward and backward stepwise procedures were used. No weights were added in this regression analysis because of the approximately equal population size of the units of analysis and because of the relatively large number of deaths in each borough. Sampling error thus formed a very limited part of the error term in the regression function. ${ }^{26}$ All analyses were performed on ranked data. Analyses on log transformed data yielded similar results and are not therefore presented separately.

\section{Results}

ASSOCIATION BETWEEN CRUDE AND AGE STANDARDISED SES MEASURES

All Spearman rank correlation coefficients between crude and age standardised SES measures are 0.95 or above. Thus, the effect of correcting the SES indicators of boroughs for their age structure is small, despite the strong association between age and most SES indicators. In table 4 Spearman rank correlations are presented.

ASSOCIATION BETWEEN SES AND MORTALITY

All associations between SES and mortality are in the expected direction - a less favourable SES value is associated with a higher SMR. The strength of the association varies widely it is strong for income, unemployment, and the first factor (which largely represents income and unemployment) and weak for educational level and the second factor (table 2). In the analysis of the proportion of the population with only a diploma from primary school, differences exist between crude and age standardised measures in relation to the SMR. No difference of any importance is found between the other crude and age standardised SES measures. Spearman correlation coefficients are given in table 5 .

Figure 2 shows the relation between SMRs and the proportion of people with only a diploma from primary school, with and without correction for the age structure of the population of boroughs. Correction for the age

Table 5 Rank correlation coefficients between indicators of socioeconomic status and standardised mortality ratios (1-64 years) per borough of Amsterdam

\begin{tabular}{|c|c|c|c|}
\hline Variable & & $R$ & $p$ value \\
\hline \multirow{2}{*}{$\begin{array}{l}\text { Education (diploma): } \\
\text { Primary school only }\end{array}$} & & & \\
\hline & $\begin{array}{l}\text { Corrected } \\
\text { Uncorrected }\end{array}$ & $\begin{array}{l}0.43 \\
0.23\end{array}$ & $<0.05$ \\
\hline \multirow{2}{*}{$\begin{array}{l}\text { Higher professional } \\
\text { university }\end{array}$} & Corrected & 0.09 & \\
\hline & Uncorrected & $0 \cdot 17$ & \\
\hline \multirow[t]{2}{*}{ Unemployment } & Corrected & $0 \cdot 85$ & $<0.001$ \\
\hline & Uncorrected & $0 \cdot 86$ & $<0.001$ \\
\hline \multirow{3}{*}{ Income } & Corrected & $-0.93^{*}$ & $<0.001$ \\
\hline & Uncorrected & $-0.94^{*}$ & $<0.001$ \\
\hline & Uncorrected & -0.90 & $<0.001$ \\
\hline \multirow{3}{*}{ First factor } & Corrected & $0.91^{*}$ & $<0.001$ \\
\hline & Uncorrected & $0.90^{*}$ & $<0.001$ \\
\hline & Uncorrected & $\begin{array}{c}0.89 \\
-0.17 *\end{array}$ & $<0.001$ \\
\hline \multirow{2}{*}{ Second factor } & $\begin{array}{l}\text { Corrected } \\
\text { Uncorrected }\end{array}$ & $\begin{array}{l}-0 \cdot 17^{*} \\
-0 \cdot 18^{*}\end{array}$ & \\
\hline & Uncorrected & -0.01 & \\
\hline
\end{tabular}

$* \mathrm{n}=17$.
Table 4 Rank correlation coefficients between crude and age standardised measures of socioeconomic status

\begin{tabular}{lll}
\hline Variable & $R$ & $p$ value \\
\hline Education (diploma): & & \\
$\quad$ Primary school only & 0.95 & $<0.001$ \\
$\quad$ Higher professional university & 0.99 & $<0.001$ \\
Unemployment & 0.98 & $<0.001$ \\
Income & $1.00^{*}$ & $<0.001$ \\
First factor & $1.00^{*}$ & $<0.001$ \\
Second factor & $0.99^{*}$ & $<0.001$ \\
\hline${ }^{*} \mathrm{n}=17$ & &
\end{tabular}


structure of boroughs causes most observations to centre along one diagonal, leaving three observations apart in the upper left quadrant of the plot. These three data points represent the inner city of Amsterdam. If these three outlying observations are omitted, the rank correlation coefficients of the standardised mortality with the proportion of people with only a diploma from primary education are 0.60 and 0.84 (both: $p<0.001$ ), with and without correction for the age structure of the populations respectively.

\section{REGRESSION}

The only variable which is selected is income, taking into account the age standardised SES measures with and without the factors from the factor analysis. Standardised regression coefficients equate correlation coefficients in this case and are therefore not presented separately. The same variable is selected using the unstandardised SES measures.

\section{Discussion}

This study shows that the age structure of boroughs in the city of Amsterdam has a small influence on the ranking of boroughs in relation to their SES. Differences in the effects of the age structure for various SES indicators
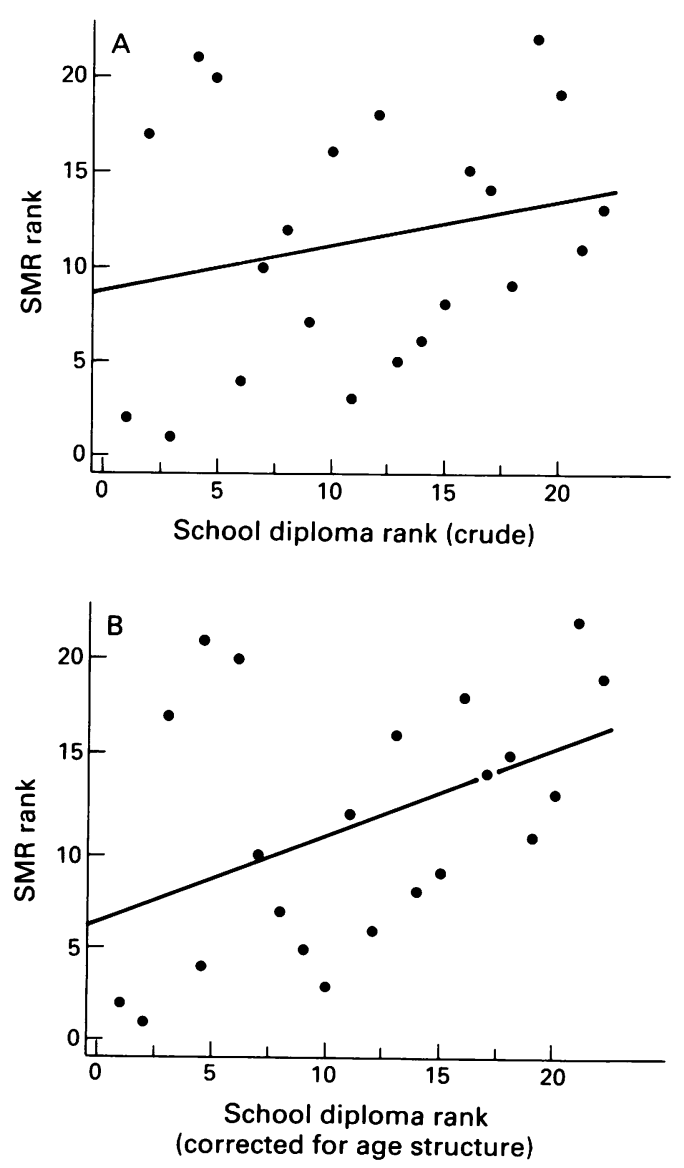

Figure 2 Plots of the ranks of boroughs according to the standardised mortality ratio (SMR) (1-64 years) in relation to their ranks in terms of the proportion of their population with only a diploma from primary school (crude and age standardised). can probably be explained by variation in measures (proportions and means) and by the kind of data (sample or whole population).

The age structure of the Amsterdam boroughs also seems to have a limited influence on the association found between the SES and SMR. One SES indicator, the proportion of people with primary school education only, is an exception and shows a relatively large change after correction for the age structure of the population. This is because the proportion of people with a primary school diploma only has a stronger association with age than the other SES indicators as a result of a cohort effect in educational participation (table 1 ).

The limited influence of the age structure of Amsterdam boroughs on the measurement of SES seems to indicate that given SES indicators do not have to be corrected for age. Correction for the age structure of the population will be more important, however, if small areas differ little with regard to SES, if they vary considerably in age structure, or if a given SES indicator shows a strong cohort effect or age association. If areas differ sufficiently in SES, the impact of varying age structures will be less important. In all these cases both the SES ranking of areas and the association between SES and mortality can be affected by the age structure. This is illustrated by our results on primary school education which show the largest change after correction for age structure. The limited influence of the age structure of the Amsterdam boroughs on the other results can also be partly explained by rather large differences in SES and socioeconomic health in this city which were also shown by research in the 1970 s and 80 s. $^{78}$

The use of a common factor in a wide range of indicators to measure the SES or deprivation of small areas, like the Jarman ${ }^{1}$ or Townsend index ${ }^{14}$ or others, ${ }^{615}$ does not automatically protect against the influence of the age structure of the populations concerned, even if age dependent indicators, such as the proportion of under $5 \mathrm{~s}$ in the Jarman index, are omitted.

Until now part of the discussion on the measurement of the SES of small areas has concentrated on the problem of cross-level bias, the "ecological fallacy", ${ }^{27-31}$ concerning inferences from group to individual health and not on the measurement of SES as such. In this paper the problem of cross-level bias is not discussed because no inferences from group to individuals are needed. Policy makers are usually interested in the populations of small areas as a whole for priority setting in public health in order to reduce or to compensate for socioeconomic health differences. For instance, public health promotion and community development are targeted at the aggregate and not at the individual level. Thus groups are the units of analysis in this study and this makes the ecological fallacy less interesting.

In measuring the SES of small areas, ideally either SES indicators which have no association with age should be used or these should be corrected for the age structure of the popu- 
lations concerned. The alternative, a situation in which the populations of all areas have the same age structure, will be very rare. It is difficult to determine in advance when such a correction is important, because this also depends on the amount of variation in SES between areas. However, if policy makers think of starting a policy aimed at reducing area-bound socioeconomic health differences, then SES differences are usually visible and thus probably rather large. A correction of the SES measure for the age structure of the population is also appropriate for research on the association between SES and health indicators of small areas. SES will be measured less precisely if the age structure of the areas concerned varies at random. This lack of precision will usually lead to an underestimation of the association between SES and mortality at the aggregate level.

The authors wish to thank W Wijker PhD for his helpful methodological comments.

1 Jarman B. Identification of underprivileged areas. $B M \mathcal{F}$ 1983;286:1705-9.

2 Smith GD. Second thoughts on the Jarman index. $B M \mathcal{F}$ 1991;302:359-60.

3 Ben-Shlomo Y, White I, McKeigue PM. Prediction of general practice workload from census based social deprivation scores $f$ Epidemiol Community Health 1992;46:532-6.

4 Centre for Policy Research (Cebeon). Distribution of money for social renewal in the Amsterdam submunicipal fund. for social renewal in the Amsterdam

Amsterdam: Cebeon, AE, Looman CWN. Cultural and economic determinants of geographical mortality pattern economic determinants of geographical mortality patterns in The Nether

6 Kunst AE, Looman CWN, Mackenbach JP. Socio-economic mortality differences in The Netherlands in 1950 1984: a regional study of cause-specific mortality. $\mathrm{Soc} S \mathrm{ci}$ Med 1990;31:141-52.

7 Lau-Ijzerman A, Habbema JDF, Van der Maas PJ, et al. Comparative study of Amsterdam boroughs on mortality, hospital admission rate and long-term occupational disability rate. Amsterdam: Municipal Health Service, 1980. [In Dutch

8 Van der Maas PJ, Habbema JDF, Van den Bos GAM, et al. Comparative study of Amsterdam neighbourhoods on Comparative study of Amsission rate, II Amsterdam University of Amsterdam, Institute of Social Medicine, University of Amste

9 Vocio-economic status and mortality differences between Rotterdam neighbour- hoods. Tijdschrift voor Sociale Gezondheidszorg 1991; 69:55-60. [In Dutch]

10 van Steenbergen J. Mortality in the city of Utrecht. Utrecht: Municipal Health Service, Dept of Epidemiology and Health Promotion, 1989. [In Dutch]

11 Struben HWA. The crisis and the health of the inhabitants of The Hague. Epidemiologisch Bulletin 's-Gravenhage 1990;25(1):10-9. [In Dutch]

12 Townsend P, Simpson D, Tibbs N. Inequalities in the city of Bristol: a preliminary review of statistical evidence. In 7 Health Serv 1985;15:637-63.

13 Brennan ME Lancashire R. Association of childhood mortality with housing status and unemployment. 7 Epidemiol Community Health 1978;32:28-33.

14 Townsend P, Phillimore P, Beattie A. Health and deprivation - inequality and the North. London: Croom Helm 1988

15 Morris R, Carstairs V. Which deprivation? A comparison of selected deprivation indexes. I Public Health Med 1991;13:318-26.

16 World Health Organisation-Europe. Healthy cities: action strategies for health promotion. Copenhagen: WHO, 1987.

17 Ashton J, ed. Healthy cities. Buckingham: Open University Press, 1992.

8 Amsterdam Municipal Health Service. Amsterdam: healthy perspective. Amsterdam: MHS, 1991. [In Dutch]

19 Townsend P, Davidson N. Inequalities in health: the Black report. Harmondsworth: Penguin, 1982.

20 Smith GD, Bartley M, Blane D. The Black report on socioeconomic inequalities in health 10 years on. $B M Y$ 1990;301:373-7.

21 Whitehead $M$, Dahlgren G. What can be done about inequalities in health? Lancet 1991;338:1059-63.

22 Liberatos P, Link BG, Kelsey JL. The measurement of social class in epidemiology. Epidemiol Rev 1988;10:87121.

23 Subcommission Socio-economic status of the Program Commission on Socio-economic health differences. To a standard-operationalisation of socio-economic status for epidemiologic and socio-medical research. The Hague: DOP, 1990. [In Dutch]

24 Doornbos JPR, Nordbeck HJ. Perinatal mortality - obstetric risk factors in a community of mixed ethnic origin in Amsterdam. Amsterdam: University of Amsterdam, 1985. ( $\mathrm{PhD}$ dissertation)

25 Rothman KJ. Modern epidemiology. Boston: Little Brown, 1986.

26 Pocock SJ, Cook DG, Shaper AG. Analysing geographic variation in cardiovascular mortality: methods and results. F $R$ Statist Soc $A$ 1982;145(3):313-41.

27 Robinson WS. Ecological correlations and the behavior of individuals. American Sociological Review 1950;15:351-7.

28 Duncan OD, Davies B. An alternative to ecological correlation. American Sociological Review 1953;18:665-6.

29 Firebaugh G. A rule for inferring individual-level relationships from aggregate data. American Sociological Review 1978;43:557-72.

30 Morgernstern $\mathrm{H}$. Uses of ecologic analysis in epidemiologic research. Am f Public Health 1982;72:1336-44.

31 Piantadosi S, Byar DP, Green SB. The ecological fallacy. Am ₹ Epidemiol 1988;127:893-904. 